\title{
Differentiation of bone mesenchymal stem cells into hepatocyte-like cells induced by liver tissue homogenate
}

\author{
X.K. Xing, H.G. Feng and Z.Q. Yuan \\ Department of Life Science and Technology, Xinxiang Medical University, \\ Xinxiang, China \\ Corresponding author: X.K. Xing \\ E-mail: biyingxiao@163.com
}

Genet. Mol. Res. 15 (3): gmr.15038550

Received February 15, 2016

Accepted April 11, 2016

Published July 15, 2016

DOI http://dx.doi.org/10.4238/gmr.15038550

Copyright $($ C 2016 The Authors. This is an open-access article distributed under the terms of the Creative Commons Attribution ShareAlike (CC BY-SA) 4.0 License.

\begin{abstract}
This study investigated the efficacy and feasibility of inducing the differentiation of bone marrow-derived mesenchymal stem cells (BMSCs) into hepatocyte-like cells in vitro using Sprague Dawley rats, as a model of hepatocyte generation for cell transplantation. BMSCs were isolated and grown using the adherent method and exposed to 5 or $10 \%$ liver tissue homogenate, before being collected for analysis after $0,7,14$, and 21 days. Immunofluorescence and western blotting were employed to detect the liver-specific markers $\alpha$-fetoprotein (AFP) and albumin (ALB). Supernatant urea content was also measured to verify that differentiation had been induced. After 7 days in the presence of $10 \%$ liver tissue homogenate, BMSCs demonstrated hepatocyte-like morphological characteristics, and with prolonged culture time, liverspecific markers were gradually produced at levels indicating cell maturation. AFP expression peaked at 14 days then began to decrease, while both urea and ALB levels increased with induction time. Overall,
\end{abstract}


marker expression in the $5 \%$ homogenate group was less than or equal to the $10 \%$ group at each time point. Thus, in a rat model, liver tissue homogenate obtained from partial hepatectomy can induce the differentiation of BMSCs into hepatocyte-like cells. This method is simple, feasible, and has remarkable real-world application potential.

Key words: Bone marrow mesenchymal stem cells; Hepatocyte-like cells; Liver tissue homogenate; Sprague Dawley rats

\section{INTRODUCTION}

Liver transplantation is an effective method for treating end-stage liver disease, but is relatively unpopular owing to its high cost, serious associated complications (such as transplant rejection), and dependence on the availability of limited donor sources. Alongside the development of tissue engineering, cell replacement therapy demonstrates promise as new technique for the treatment of liver diseases and other severe conditions. Cell replacement with bone marrow-derived mesenchymal stem cells (BMSCs) represents a novel approach to treating end-stage liver disease. As seed cells, BMSCs exhibit strong proliferation and differentiation ability, limited immune rejection, and can be acquired from a wide range of sources. They are also readily and ethically obtainable and demonstrate high biocompatibility (Kemp et al., 2005; Hang and Xia, 2014; Yuan et al., 2014; Marquez-Curtis et al., 2015). For these reasons, it is of sizeable practical value to explore methods by which BMSCs can be induced to differentiate into liver cells, to establish safe, feasible, and effective clinical treatment options.

\section{MATERIAL AND METHODS}

\section{Materials}

Low-glucose Dulbecco's modified Eagle's medium (L-DMEM) was purchased from Gibco (Carlsbad, CA, USA), fetal bovine serum (FBS) from HyClone (Logan, UT, USA), trypsin from Sigma (St. Louis, MO, USA), and $\alpha$-fetoprotein (AFP) and albumin (ALB) from Santa Cruz Biotechnology (Dallas, TX, USA). Sprague Dawley (SD) rats were purchased from the Laboratory Animal Center of Xinxiang Medical University, Xinxiang, China. The treatment of animals over the course of the study complied with the current Animal Protection Law of China.

\section{Isolation and culture of rat BMSCs}

Four- to six-week-old healthy male SD rats (weighing 100-150 g) were euthanized by cervical dislocation, and bilateral femurs and tibias were separated. All procedures took place under sterile conditions. Bone marrow was washed with L-DMEM (containing $100 \mathrm{U} /$ $\mathrm{mL}$ penicillin, $100 \mathrm{U} / \mathrm{mL}$ streptomycin, and $10 \% \mathrm{FBS}$ ), then placed into a centrifuge tube to create a single-cell suspension, and centrifuged at $1000 \mathrm{rpm}$ for 5 min before discarding the supernatant. Cells were then mixed with fresh medium, before being seeded in a culture flask and incubated at $37^{\circ} \mathrm{C}$ in a $5 \% \mathrm{CO}_{2}$ atmosphere. The medium was half-changed after $48 \mathrm{~h}$,

Genetics and Molecular Research 15 (3): gmr.15038550 
then fully replaced every 3 days for the duration of the study. Cells were passaged at $80 \%$ confluency by using a split ratio of approximately 1:3.

\section{BMSC growth curves}

First, third, and fifth generation cultures demonstrating good growth were digested with $0.25 \%$ trypsin, and $1 \times 10^{4}$ cells $/ \mathrm{mL}$ from each was seeded on a 24 -well plate. Each 3-well group was examined daily for 1 week after inoculation to obtain cell counts, and the mean values were calculated. Growth curves were subsequently drawn as plots of culture time vs cell number.

\section{Liver tissue homogenates}

Under sterile conditions, 6 rats were anaesthetized using ether and incised below the xiphoid approximately $1-2 \mathrm{~cm}$ along the ventral midline to open the abdominal cavity. The left lobe and middle of the liver were resected (accounting for $68 \%$ of total liver weight), and the wound was closed and sprinkled with sulfanilamide to prevent infection. Rats were routinely fed before being sacrificed $12 \mathrm{~h}$ after surgery. Culture medium was then added to liver tissue homogenate ( $1 \mathrm{~mL}$ L-DMEM for $200 \mathrm{mg}$ homogenate) at $4^{\circ} \mathrm{C}$, and centrifuged at 12,000 rpm for $25 \mathrm{~min}$. Supernatant was removed, then samples were passed through a $0.22-\mu \mathrm{m}$ filter and stored at $-20^{\circ} \mathrm{C}$ until needed for all subsequent analyses.

\section{Induced BMSC differentiation}

Third-generation cells $\left(2 \times 10^{4} /\right.$ well) were seeded on $35-\mathrm{mm}$ culture dishes at $37^{\circ} \mathrm{C}$ in a $5 \% \mathrm{CO}_{2}$ atmosphere. For the experimental groups, 5 or $10 \%$ liver homogenate was added to L-DMEM containing 10\% FBS. After 0, 7, 14, and 21 days, cell morphology was observed under an inverted microscope. The medium contained liver homogenate was changed every 3 days. The control group consisted of the same cells treated with L-DMEM and 10\% FBS only. Each experiment was repeated 3 times.

\section{Immunofluorescence assay}

Cells were collected at 7, 14, and 21 days to produce cell smears. Smears were fixed for 10 min with $4 \%$ formaldehyde, washed 3 times with phosphate-buffered saline (PBS), incubated with $0.1 \%$ Triton X-100 for 10 min, blocked with $10 \%$ sheep serum for $30 \mathrm{~min}$ at room temperature, and then treated with $0.3 \% \mathrm{H}_{2} \mathrm{O}_{2}$ for $15 \mathrm{~min}$. Cells were incubated overnight at $4{ }^{\circ} \mathrm{C}$ with primary antibodies against AFP or ALB, before being washed with PBS and exposed to biotin-labeled secondary antibodies. After a further incubation with streptavidin-fluorescein isothiocyanate for $60 \mathrm{~min}$, cells were observed under an ECLIPSE 80i fluorescence microscope (Nikon, Tokyo, Japan).

\section{Western blot analysis}

Cells induced for $0,7,14$, and 21 days were examined for AFP and ALB expression. Samples underwent $12 \%$ sodium dodecyl sulfate-polyacrylamide gel electrophoresis at 80

Genetics and Molecular Research 15 (3): gmr.15038550 
$\mathrm{mA}$ for $2 \mathrm{~h}$, and the proteins were then transferred onto polyvinylidene fluoride membranes and incubated with AFP or ALB antibodies for $1 \mathrm{~h}$, before being exposed to horseradish peroxidase-conjugated secondary antibodies, and visualized by enhanced chemiluminescence.

\section{Liver cell function test}

Supernatant was collected from samples of cells cultured for $0,7,14$, and 21 days, and glutamate dehydrogenase was used to measure urea concentration, from which urea level curves were drawn.

\section{Statistical analysis}

Two-factor analyses of variance were conducted using SPSS 13.0 (SPSS Inc., Chicago, IL, USA) with an $\alpha$-level of 0.05 , based on repeated measurements.

\section{RESULTS}

\section{Cell morphology}

As shown below, we observed bone marrow cell component complexes after 1-2 days in primary cultures, with a few irregular, long, spindle-shaped and polygonal cells attached to the wall of the culture vessel. After receiving a new half dose of the medium contained liver homogenate, cells began to proliferate rapidly, establishing a colony. At this point, 7 to 9 cells (mainly spindle-shaped) covered the bottom of the culture bottle with more than $95 \%$ fusion. The cells took on a whirlpool shape. After passage, cells grew with greater speed and continued to attach themselves to the container wall. Two hours later, more were affixed to the wall, and within $24 \mathrm{~h}$, they had become completely adherent. After 6-7 days, cells completely covered the bottom of the culture bottle. Their morphology became highly homogeneous (spindle-shaped) and presented an overall whirlpool shape (Figure 1A). As culture time after addition of liver homogenate extended, the number of ovoid, circular, and irregular polygonal cells gradually grew (Figure 1B).

A

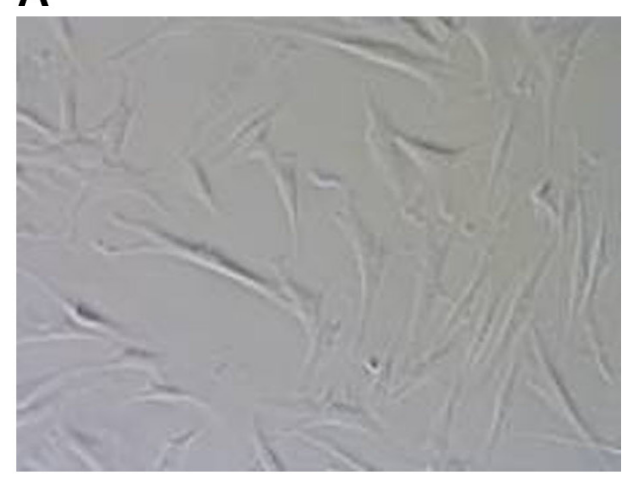

B

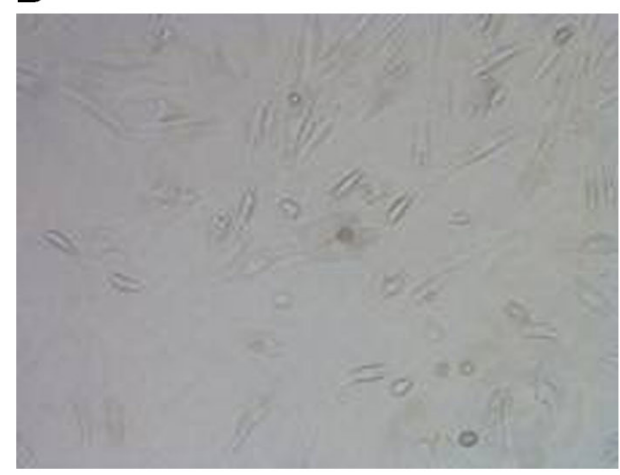

Figure 1. Bone marrow-derived mesenchymal stem cell morphology. A. Not induced. B. Induced. 


\section{Cell growth curves}

Growth curves for first-, third-, and fifth-generation cells were essentially similar. After 1-2 days, there was adaptation from the latent to the logarithmic phase, and 3-5 days later, the curves began to plateau (Figure 2).

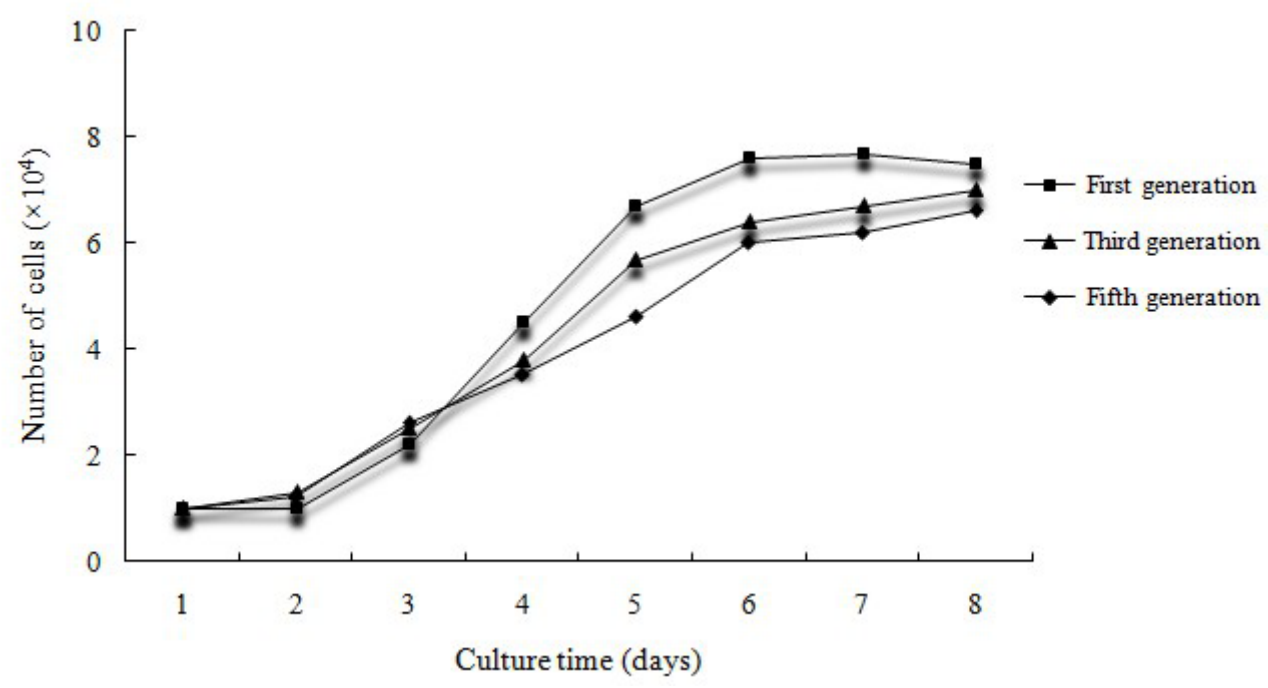

Figure 2. Bone marrow-derived mesenchymal stem cell growth curves.

\section{AFP and ALB levels assessed by immunofluorescence}

AFP and ALB were not expressed by BMSC cells in the absence of liver homogenate. Levels of AFP were higher at 7 and 14 days in the 10\% liver tissue homogenate group, and decreased with further culture time. Expression of ALB was higher at 7 days in the presence of $10 \%$ liver tissue homogenate and increased with time, reaching its maximum at 21 days. The expression of ALB and AFP in the 5\% homogenate group was consistently equal to or less than that of the $10 \%$ group at each time point (Table 1 and Figure 3).

Table 1. Proportions of $\alpha$-fetoprotein (AFP)-positive and albumin (ALB)-positive bone marrow-derived
mesenchymal stem cells in each group.
\begin{tabular}{l|c|c|c}
\hline Concentration & Culture time (days) & AFP & ALB \\
\hline $5 \%$ & 0 & - & - \\
\cline { 2 - 4 } & 7 & + & + \\
\cline { 2 - 4 } & 14 & ++ & + \\
\cline { 2 - 4 } & 21 & ++ & + \\
\cline { 2 - 4 } & 0 & + & ++ \\
\cline { 2 - 4 } & 7 & +++ & +++ \\
\cline { 2 - 4 }
\end{tabular}

(-) Negative; $( \pm$ ) few positive; (+) $10-20 \%$ positive; (++) $20-30 \%$ positive; $(+++) 30-40 \%$ positive. 
A

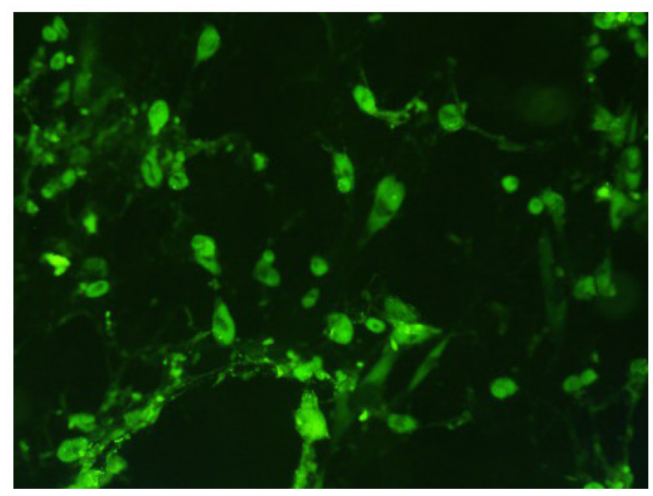

B

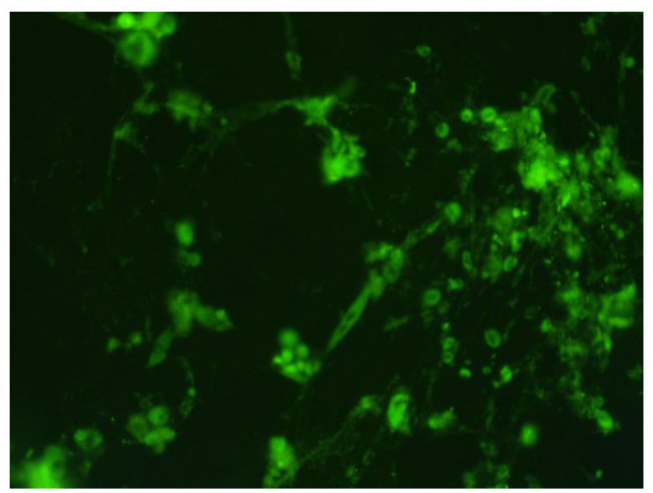

Figure 3. $\alpha$-Fetoprotein (AFP) and albumin (ALB) expression in $10 \%$ liver tissue homogenate-induced cells detected by immunofluorescence. A. AFP expression on the 14th day. B. ALB expression on the 21st day.

\section{ALB and AFP levels assessed by western blot}

ALB and AFP expression was detected by western blot at different time points after induction of differentiation with liver tissue homogenate. The expression of these markers in the $10 \%$ liver homogenate samples was greater than that of cells exposed to $5 \%$ homogenate, and AFP levels in both groups peaked at 14 days. ALB expression increased as culture time progressed, reaching a maximum at 21 days (Figure 4).

\section{7 days 14 days 21 days}

\section{$5 \%$-AFP \\ $5 \%$-ALB \\ $10 \%-\mathrm{AFP}$}

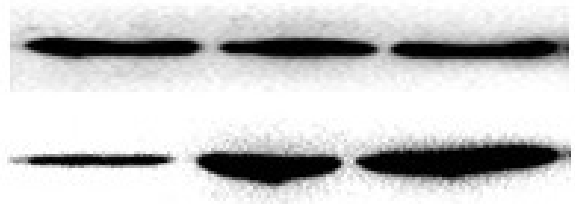

$10 \%$-ALB

\section{GAPDH}

Figure 4. $\alpha$-Fetoprotein (AFP) and albumin (ALB) expression detected by western blot after induction of bone marrow-derived mesenchymal stem cells by 5 and $10 \%$ liver tissue homogenate. GAPDH $=$ glyceraldehyde 3-phosphate dehydrogenase. 


\section{Liver cell metabolism}

Urea concentration in culture supernatants was plotted for each group as the line chart shown below. No urea was detected at any time point in control cultures, but it was produced after 7 days by cells in the 5 and $10 \%$ homogenate groups. For each concentration, urea levels increased as time progressed. At each time point, the difference between the two groups was statistically significant $(\mathrm{P}<0.05$; Figure 5$)$.

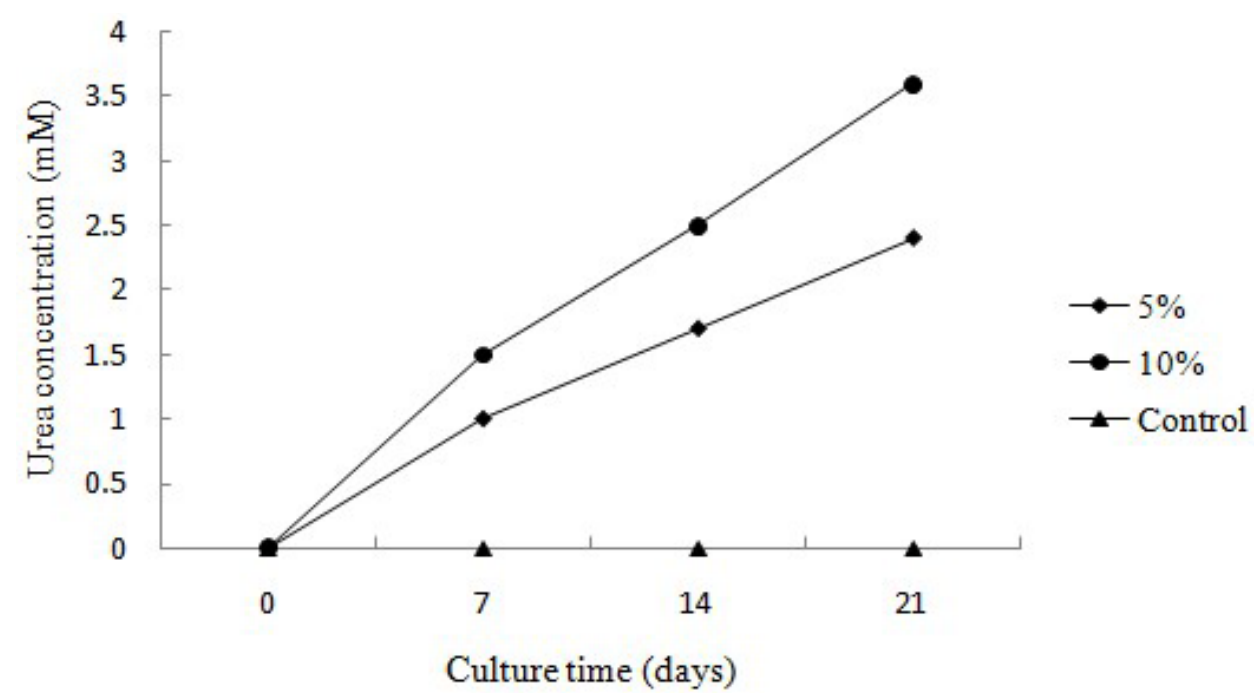

Figure 5. Urea concentration in culture supernatant sat several time points after induction.

\section{DISCUSSION}

Stem cell research has progressed significantly in recent years. Certain stem cells in bone marrow, in particular, can be induced to differentiate into various cell types. In vitro culture of such cells, a particularly exciting research area, can employ conditions promoting proliferation and differentiation into hepatocytes. Liver cells obtained in this way may be transplanted or used to generate biological artificial livers, representing extraordinary potential therapeutic value.

Mesenchymal stem cells are rare in bone marrow. The proportion of mononuclear cells in this tissue is only $0.001-0.1 \%$, and gradually decreases with age. The bone marrow of young rats contains a greater number of immature cells. At present, there is no universally accepted method for the isolation, purification, or culture of BMSCs. Instead, four general categories of isolation technique exist: adherent culture (Zohar et al., 1997), density gradient centrifugation (Nuttall et al., 1998), flow cytometry, and immunomagnetic bead separation (Ghilzon et al., 1999). The adherent method is based on the characteristics of cells in suspension and hematopoietic system growth, and consists of the removal of non-adhering hematopoietic cells. This technique takes advantage of the attributes of BMSCs for purification, such as the ease with which they are detached, and their differences from lymphocytes and monocytes.

Genetics and Molecular Research 15 (3): gmr.15038550 
The adherent culturing method has the advantages of being simple, fast, and having minimal effects on cell behavior.

BMSCs can thus be isolated and expanded in vitro, and are able to differentiate into histiocytes stemming from mesoderm and neuroectoderm. The differentiation of stem cells is largely determined by their microenvironment (Faia-Torres et al., 2015; Lu et al., 2015; Tao et al., 2015). Currently, in vitro differentiation into hepatocytes is generally achieved using cytokines, but the optimum induction conditions and whether or not the resulting cells fully possess the characteristics of hepatocytes remain unconfirmed.

Hepatocyte growth factors (HGF) are largely produced by hepatic Kupffer cells and sinusoidal endothelial cells. Owing to their mitogenicity, HGFs play an important role in liver development, maturation, and regeneration (Suárez-Causado et al., 2015). HGFs can stimulate the proliferation of hepatocytes, various epithelial cells, endothelial cells, chondrocytes, and neurocytes, promote various types of cellular movement and morphological changes (Lehwald et al., 2014), and inhibit apoptosis (Gohda, 2002). To this effect, HGF addition is commonly used for liver stem cell differentiation in in vitro experiments (Liu et al., 2015; Wang et al., 2015).

Fibroblast growth factor 4 is a multifunctional cell growth factor produced by endothelial cells that plays an important role in endoderm formation. In vivo, endothelial cells promote chemotaxis and mitosis, and encourage the formation and development of the embryonic liver (Jung et al., 1999; Minagawa et al., 2009). Epidermal growth factor (Zhou et al., 2015), insulin, transferrin, selenium, and other nutritive factors also play crucial roles in the development and regeneration of liver cells. Cytokines are the main initiators of hepatocyte DNA synthesis, but their growth, differentiation, and proliferation are regulated by the entire organism, including many extra- and intra-hepatic influences and certain hormones.

The human body's capacity for liver regeneration following damage or partial removal has been well established. In a normal physiological state, approximately $0.0012-0.01 \%$ of rat liver cells are undergoing mitosis (Fausto et al., 2012; Michalopoulos, 2014). After injury or surgical removal of the cause of injury, liver cells quickly begin to proliferate and recover the lost organ weight (Cienfuegos et al., 2014). Post-hepatectomy liver tissue homogenates are likely to include all necessary stimulating factors and nutrients (Karkampouna et al., 2012; Maruyama and Ohkohchi, 2012; Kedarisetty et al., 2014; Fan et al., 2015). The present study used homogenates generated following partial resection of rat liver tissue to analyze the combined action of liver cell growth factors and hormones on stem cell differentiation.

AFP, ALB, and other liver cell-specific markers were measured. AFP is a cytosolic protein secreted by liver precursor cells. As the cells gradually mature, they no longer express AFP (Lai et al., 2015; Takeyama et al., 2015). ALB, synthesized by liver cells and secreted into the circulatory system, is the most abundant protein in the plasma of healthy human beings. This protein is the most commonly used and most reliable indicator of liver cell function, as very little is produced by cells of other tissues (Kahraman et al., 2014; Tsipotis et al., 2015). The liver's ability to metabolize amino acids is facilitated by the synthesis of urea from ammonia and subsequent renal excretion. Urea is primarily produced by the liver and kidneys, although a very small amount is generated in the brain.

Our experiment showed that rat BMSCs did not produce AFP, ALB, and urea unless treated with partial hepatectomy liver tissue homogenate. After induction with this homogenate, however, BMSC AFP expression reached its peak at 14 days, and then decreased with time. In the presence of $10 \%$ liver tissue homogenate, ALB and urea production was low after 7 days, but increased over time until reaching a maximum at 21 days. In this investigation, we

Genetics and Molecular Research 15 (3): gmr.15038550 
identified the necessary factors for the differentiation of BMSCs into mature liver cells, based on the measurement of multiple markers over an extended induction time. The ability of rat liver cells to secrete ALB and urea gradually increased over the study period. We assert that these cells function in a similar manner to mature hepatocytes, and that the differentiation of BMSCs into hepatocytes in vitro was successfully accomplished in the present study.

In this experiment, liver cell phenotype and function were assessed according to two distinct aspects of multiple indicators. As induction time increased, the markers tested gradually showed signs of cell maturation. Here, the effects of partial hepatectomy liver tissue homogenate on the differentiation of BMSCs into liver cells were demonstrated in a rat model and analyzed at length. We hope that our findings prove to be a valuable reference for future studies related to this issue. Further examination of the proposed method and assessments of the reliability and safety of the induction and differentiation mechanism described will be necessary, in addition to an appraisal of its clinical application.

\section{Conflicts of interest}

The authors declare no conflict of interest.

\section{ACKNOWLEDGMENTS}

Research supported by research grants from the Key Research Project of Henan Province (\#15A180020) and the Cooperation Projects of Henan Province and the Chinese Academy of Sciences (\#102106000017).

\section{REFERENCES}

Cienfuegos JA, Rotellar F, Baixauli J, Martínez-Regueira F, et al. (2014). Liver regeneration - the best kept secret. A model of tissue injury response. Rev. Esp. Enferm. Dig. 106: 171-194.

Faia-Torres AB, Charnley M, Goren T, Guimond-Lischer S, et al. (2015). Osteogenic differentiation of human mesenchymal stem cells in the absence of osteogenic supplements: A surface-roughness gradient study. Acta Biomater. 28: 64-75. http://dx.doi.org/10.1016/j.actbio.2015.09.028

Fan M, Wang X, Xu G, Yan Q, et al. (2015). Bile acid signaling and liver regeneration. Biochim. Biophys. Acta 1849: 196-200. http://dx.doi.org/10.1016/j.bbagrm.2014.05.021

Fausto N, Campbell JS and Riehle KJ (2012). Liver regeneration. J. Hepatol. 57: 692-694. http://dx.doi.org/10.1016/j. jhep.2012.04.016

Ghilzon R, McCulloch CA and Zohar R (1999). Stromal mesenchymal progenitor cells. Leuk. Lymphoma 32: 211-221. http://dx.doi.org/10.3109/10428199909167382

Gohda E (2002). Function and regulation of production of hepatocyte growth factor (HGF). Nihon Yakurigaku Zasshi 119: 287-309.

Hang HL and Xia Q (2014). Role of BMSCs in liver regeneration and metastasis after hepatectomy. World J. Gastroenterol. 20: 126-132. http://dx.doi.org/10.3748/wig.v20.i1.126

Jung J, Zheng M, Goldfarb M and Zaret KS (1999). Initiation of mammalian liver development from endoderm by fibroblast growth factors. Science 284: 1998-2003. http://dx.doi.org/10.1126/science.284.5422.1998

Kahraman A, Wand K, Eisele L, Witzke O, et al. (2014). Comparison of extracorporeal liver assist devices - albumin dialysis versus plasma exchange - in acute-on-chronic liver failure. Dtsch. Med. Wochenschr. 139: 1653-1658.

Karkampouna S, Ten Dijke P, Dooley S and Julio MK (2012). TGFb signaling in liver regeneration. Curr. Pharm. Des. 18: 4103-4113. http://dx.doi.org/10.2174/138161212802430521

Kedarisetty CK, Anand L, Khanam A, Kumar A, et al. (2014). Growth factors enhance liver regeneration in acute-onchronic liver failure. Hepatol. Int. 8 (Suppl 2): 514-525. http://dx.doi.org/10.1007/s12072-014-9538-4

Kemp KC, Hows J and Donaldson C (2005). Bone marrow-derived mesenchymal stem cells. Leuk. Lymphoma 46: 1531-

Genetics and Molecular Research 15 (3): gmr.15038550 
1544. http://dx.doi.org/10.1080/10428190500215076

Lai Q, Levi Sandri GB and Lerut J (2015). Selection tool alpha-fetoprotein for patients waiting for liver transplantation: How to easily manage a fractal algorithm. World J. Hepatol. 7: 1899-1904. http://dx.doi.org/10.4254/wjh.v7.i15.1899

Lehwald N, Duhme C, Wildner M, Kuhn S, et al. (2014). HGF and SDF-1-mediated mobilization of CD133+ BMSC for hepatic regeneration following extensive liver resection. Liver Int. 34: 89-101. http://dx.doi.org/10.1111/liv.12195

Liu T, Peng Y, Jia C, Fang X, et al. (2015). Hepatocyte growth factor-modified adipose tissue-derived stem cells improve erectile function in streptozotocin-induced diabetic rats. Growth Factors 33: 282-289. http://dx.doi.org/10.3109/08 977194.2015.1077825

Lu T, Huang YX, Zhang C, Chai MX, et al. (2015). Effect of pulsed electromagnetic field therapy on the osteogenic and adipogenic differentiation of bone marrow mesenchymal stem cells. Genet. Mol. Res. 14: 11535-11542. http://dx.doi. org $/ 10.4238 / 2015$. September.28.5

Marquez-Curtis LA, Janowska-Wieczorek A, McGann LE and Elliott JA (2015). Mesenchymal stromal cells derived from various tissues: Biological, clinical and cryopreservation aspects. Cryobiology 71: 181-197. http://dx.doi. org/10.1016/j.cryobiol.2015.07.003

Maruyama T and Ohkohchi N (2012). Platelets and liver regeneration. Seikagaku 84: 693-698.

Michalopoulos GK (2014). Advances in liver regeneration. Expert Rev. Gastroenterol. Hepatol. 8: 897-907. http://dx.doi. org/10.1586/17474124.2014.934358

Minagawa K, Koyama T and Miyoshi H (2009). Stimulating effects of fibroblast growth factors on hepatic function of fetal liver cells synergistically with oncostatin M in three-dimensional culture. J. Biosci. Bioeng. 107: 307-311. http:// dx.doi.org/10.1016/j.jbiosc.2008.10.004

Nuttall ME, Patton AJ, Olivera DL, Nadeau DP, et al. (1998). Human trabecular bone cells are able to express both osteoblastic and adipocytic phenotype: implications for osteopenic disorders. J. Bone Miner. Res. 13: 371-382. http:// dx.doi.org/10.1359/jbmr.1998.13.3.371

Suárez-Causado A, Caballero-Díaz D, Bertrán E, Roncero C, et al. (2015). HGF/c-Met signaling promotes liver progenitor cell migration and invasion by an epithelial-mesenchymal transition-independent, phosphatidyl inositol-3 kinase-dependent pathway in an in vitro model. Biochim. Biophys. Acta 1853 (10 Pt A): 2453-2463. http://dx.doi. org/10.1016/j.bbamcr.2015.05.017

Takeyama E, Tanaka M, Fujishiro J, Kitagawa N, et al. (2015). A case of alpha-fetoprotein-producing gastric cancer in a child presenting with rupture of multiple liver metastases. Pediatr. Surg. Int. 31: 885-888. http://dx.doi.org/10.1007/ $\underline{\mathrm{s} 00383-015-3724-\mathrm{x}}$

Tao Y, Zhou X, Liang C, Li H, et al. (2015). TGF-b3 and IGF-1 synergy ameliorates nucleus pulposus mesenchymal stem cell differentiation towards the nucleus pulposus cell type through MAPK/ERK signaling. Growth Factors 33: 326336. http://dx.doi.org/10.3109/08977194.2015.1088532

Tsipotis E, Shuja A and Jaber BL (2015). Albumin dialysis for liver failure: a systematic review. Adv. Chronic Kidney Dis. 22: 382-390. http://dx.doi.org/10.1053/j.ackd.2015.05.004

Wang H, Sun RT, Li Y, Yang YF, et al. (2015). HGF gene modification in mesenchymal stem cells reduces radiationinduced intestinal injury by modulating immunity. PLoS One 10: e0124420. http://dx.doi.org/10.1371/journal. pone. 0124420

Yuan SF, Jiang T, Sun LH, Zheng RJ, et al. (2014). Use of bone mesenchymal stem cells to treat rats with acute liver failure. Genet. Mol. Res. 13: 6962-6980. http://dx.doi.org/10.4238/2014.April.30.10

Zhou B, Fan Y, Rao J, Xu Z, et al. (2015). Matrix metalloproteinases-9 deficiency impairs liver regeneration through epidermal growth factor receptor signaling in partial hepatectomy mice. J. Surg. Res. 197: 201-209. http://dx.doi. org/10.1016/j.jss.2015.03.081

Zohar R, Sodek J and McCulloch CA (1997). Characterization of stromal progenitor cells enriched by flow cytometry. Blood 90: 3471-3481.

Genetics and Molecular Research 15 (3): gmr.15038550 